\title{
CONTRIBUIÇÃO PARA A QUESTÃO DAS TECNOLOGIAS DIGITAIS NOS PROCESSOS DE ENSINO-APRENDIZAGEM DE MÚSICA
}

\author{
Issues about digital technologies in the music learning \\ and teaching processes
}

\author{
MARCOS ANDRÉ MARTINS ARISTIDES \\ Universidade Federal do Ceará - campus Sobral \\ maaristides@gmail.com
}

REgINA MARCIA SimÃo SANTOS

Universidade Federal do Estado do Rio de Janeiro

regina.marcia.simao@gmail.com

\begin{abstract}
Resumo: Este ensaio trata da questão dos dispositivos digitais para o ensino-aprendizado de música, na perspectiva da mediação didática, e do lugar do docente como mediador entre o conhecimento musical e a concepção/produção de softwares e outros ambientes digitais destinados à educação musical. Para tanto, buscamos fundamentar nossos propósitos nos conceitos de transposição didática e de situação didática. Discutimos o papel que as tecnologias digitais podem desempenhar no ensino-aprendizado da música no contexto da educação básica, sugerindo que o docente se torne conceptor de meios (mídias) digitais para a educação musical em diversos formatos e tipos de dinâmica: jogos, cenários investigativos, atividade criativa etc. Consideramos, por fim, a perspectiva de que o próprio docente se torne produtor destes meios (mídias) digitais para a educação musical. Ilustramos nosso propósito com duas propostas, desenvolvidas por docentes em atividades de pesquisa institucional, que envolvem dispositivos digitais. Ao apresentar novos tipos de objetos de aprendizagem, as referidas propostas suscitam o surgimento de questões referentes à formação docente e pedagógica.
\end{abstract}

Palavras-chave: Dispositivos digitais em educação. Transposição didática. Mediação didática.

\begin{abstract}
This essay deals with the issue of digital devices for teaching music learning, under didactic mediation perspective and the place of the teacher as a mediating agent between musical knowledge and education. We seek to base our purposes on the didactic transposition and didactic situations concepts. Besides, we discuss the role that digital technologies can play in teaching-learning music in the basic education context. As well as the unfolding of the role of the teacher as a mediator between knowledge and the software production sector, to design and under certain conditions producer of digital material like: games, research scenarios, creative activity, etc., illustrating our proposal with two-piece digital devices proposed by teachers. At last, we discuss about issues related to the music teacher training and the new pedagogical situations brought by digital technologies.
\end{abstract}

Keywords: Educational digital devices. Didactic transposition. Didactic mediation. 


\section{INTRODUÇÃO}

O presente artigo, em forma de ensaio dissertativo, tem como objetivo contribuir para a compreensão do processo de didatização do conhecimento musical no âmbito escolar, discutindo as condições para que os softwares destinados à educação musical constituam aliados efetivos das atividades didático-pedagógicas em música, na perspectiva de uma pedagogia aberta. Regina M. Santos, coautora deste artigo, considera que uma pedagogia aberta diz respeito a experiências de problematização diante de um mundo que emite signos que nos afetam e forçam a pensar. Pedagogia aberta diz respeito a uma situação que é sempre imanente, uma pedagogia que se contrapõe ao ensino transmissivo, diretivo e prescritivo, com alto grau de controle e previsibilidade (Santos, 2017). Ainda segundo Santos, a pedagogia aberta diz de uma aprendizagem com "mestres [...] que sabem emitir signos a serem desenvolvidos no heterogêneo" (Deleuze, 2006, p. 48) e onde há "criação, geração de diferenças" (Gallo, 2003, p. 8). No curso deste ensaio, ao nos referirmos a Terrien (2012, 2014), Chevallard (1991), Houssaye (1992), Brousseau $(1988,2011)$ e Lopes (1999), nos colocaremos ante uma pedagogia aberta, visto que os autores defendem um sistema de interações na situação didática, um conhecimento escolar constituído na trama de relações entre os sujeitos, redimensionado a partir da mediação desses protagonistas, e Terrien enfatiza a articulação da educação musical com as tecnologias digitais através de um conjunto de ações e interações que emerjam das situações de ensinoaprendizagem.

Como objetivos específicos, propomos discutir o uso das tecnologias como suporte ao ensino-aprendizagem de música, assim como identificar o lugar do docente como agente mediador entre o conhecimento musical e a concepção/produção de dispositivos e objetos de ensino-aprendizagem em formato digital. O termo genérico software será usado para designar o conjunto de programas de informática. Entram na categoria de softwares tanto os chamados aplicativos (ou apps) como os sistemas informáticos de educação a distância. ${ }^{1}$ Estes sistemas são ferramentas de informática que fornecem as bases para a construção de ambientes virtuais de aprendizagem. Por exemplo: Moodle, Drupal e outros (Gohn, 2009; Paiva, 2010).

No contexto de planos nacionais e do "direito" de todos os alunos da educação básica à aprendizagem de um conhecimento de forma sistematizada (Brasil, 2017, p. 27, 36, 329), é de se perguntar como conceber, especificar² e

\footnotetext{
${ }^{1}$ Conhecidos pelo acrônimo LSM, em língua inglesa: Learning Management System (Sistema de gestão de aprendizagem).

${ }^{2}$ A concepção de um aplicativo consiste na descrição da atividade que se quer propor ao estudante. Se for criação com ritmos, por exemplo, será necessário então declinar esta concepção em termos de especificação de softwares: definir o objetivo específico da atividade (por exemplo, exercitar a combinação de diversos
} 
desenvolver (produzir) aplicativos que cumpram o papel de mediações didáticas. Como garantir a criação de objetos de ensino instigadores da curiosidade epistemológica? Como tratar de sequências didáticas e da produção de objetos de ensino abrigando trajetos cartográficos dos sujeitos da experiência entre o comum e o singular? Como tratar da invenção de objetos de ensino, considerando uma matriz de conhecimento não linear que "não tem nem início nem fim", mas "pontos de interseção e focos" (Doll, 1997, p. 178), lançando "ideias em todas as combinações possiveis" (p. 161)? No tocante às tecnologias digitais, tema de interesse central neste artigo, como elaborar aplicativos que funcionem como disparadores desses pontos de interseção e múltiplos focos?

Tais questões nos fazem refletir sobre o papel do professor ao transformar conhecimentos, práticas e valores da cultura em objetivos, conteúdos de ensino, programas e trabalho escolar. São as transformações de saberes cultos em saberes a serem ensinados que Verret (1975) chamou de transposição didática, noção que foi desenvolvida mais tarde por Chevallard (1991) e discutida, entre outros, por Perrenoud (1999a, p. 73-75; 1999b, p. $70-71 ; 1993$, p. 24-28; 1998). Uma vez que a transposição didática tem como foco os saberes a serem ensinados, cabe ao docente propô-los aos seus estudantes através das situações didáticas. Brousseau (1998) usa a expressão "situações didáticas" para se referir ao momento em que o professor e o aluno se colocam em interação com o saber, dentro de um quadro de atividades regido por um contrato tácito que define o que se deve esperar de cada um dos atores da situação didática (Brousseau, 1984, 1998). Contudo, entendemos que, em música, as funções dessa transformação de saberes deveriam ir além do que Terrien estabelece como sendo as de "organizar em fases sucessivas a superação das dificuldades" e de "revelar as microdificuldades permitindo prepará-las para [que o aluno possa] superálas mais facilmente" (Terrien, 2012, p. 9).

Propomos uma discussão sobre o papel do professor de música na avaliação e na produção de softwares destinados à educação musical na perspectiva de uma pedagogia aberta, apoiados pelas orientações da Base Nacional Comum Curricular em relação às tecnologias (Brasil, 2017, p. 17). ${ }^{3}$ Tanto a situação didática como a transposição didática são conceitos que constituirão os fundamentos teóricos da discussão aqui proposta, visto que adotamos a premissa segundo a qual todo aplicativo educacional está estruturado, de maneira clara ou subjacente, sobre um processo de transposição didática.

\footnotetext{
valores rítmicos) e indicar as ações dos estudantes sobre os elementos apresentados na tela (figuras rítmicas para arrastar, clicar, sobrepor etc.). A produção do software será realizada a partir da concepção.

${ }^{3}$ Dentre as decisões que caracterizam o currículo em ação, considerando o contexto e as características dos alunos, a BNCC destaca a de "selecionar, produzir, aplicar e avaliar recursos didáticos e tecnológicos para apoiar o processo de ensinar e aprender" (Brasil, 2017, p. 17).
} 
A adequação aos objetivos, a facilidade de uso e a aceitação do aplicativo pelos alunos são fatores que propiciam a criação de situações didáticas envolvendo aplicativos digitais. Em consequência, cabe ao professor analisar e validar o aplicativo (ou não) identificando a transposição didática subjacente e em função da sua adequação aos objetivos didáticos, à facilidade de uso e à aceitação deste aplicativo pelos alunos. ${ }^{4}$ Assim, estes últimos se beneficiariam de um enfoque adequado ao seu aprendizado, enquanto o/a docente trabalharia com um suporte didático cuja manipulação teria mais chances de favorecer a dinâmica de aula.

Veiga (2001) destaca que o computador é um "aliado" do professor, e, com base nesta perspectiva, afirmamos que as ferramentas digitais na aprendizagem são parte desta aliança, "propiciando transformações no ambiente de aprender e questionando as formas de ensinar" (Veiga, 2001, p. 1). As ferramentas digitais constituem um aliado que instiga pensar o ensino e a aprendizagem, numa perspectiva de pedagogia aberta.

\section{O PROBLEMA DA APROPRIAÇÃO DAS TECNOLOGIAS DIGITAIS PELOS PROFESSORES DE MÚSICA}

O desenvolvimento das tecnologias da informática tem permitido mudanças profundas no cotidiano de nossas sociedades. Contudo, na sua experiência na formação continuada em tecnologias digitais para professores de música, Aristides, coautor deste trabalho, pôde observar o pouco uso de ferramentas digitais que os professores fazem em sala de aula, se comparado com o uso das tecnologias nos seus cotidianos fora da escola. De certo modo, este testemunho pessoal confirma a tese de Rabardel e Samurçay (2006), segundo a qual um artefato só se torna ferramenta na medida em que, no contexto de uma atividade humana, coloca em relação sujeito e objeto. Diante disso, podemos considerar que a adoção e a apropriação das tecnologias digitais subentendem uma construção cultural: os esforços do estudante e/ou do educador para adotar ferramentas digitais estão diretamente relacionados com o valor que o meio sociocultural atribui a estas ferramentas.

Mesmo em regiões pobres da África, expande-se a utilização de meios digitais nas comunicações, nos mecanismos de fornecimento de energia, em outros serviços e nas transações comerciais. No seu relatório "Objetivos do Milênio para o Desenvolvimento" (ONU, 2011), a Organização das Nações Unidas refere-se a práticas inovadoras com base nas tecnologias digitais.

Usualmente as atividades de formação via internet articulam, em uma mesma plataforma, conteúdo em formato áudio, vídeo, imagens estáticas e texto. Nos últimos anos, verifica-se o aumento exponencial da oferta dos

\footnotetext{
${ }^{4}$ Uma das condições para o sucesso na adoção de ferramentas digitais é o seu domínio pelos formadores. Da mesma forma, um bom conhecimento do entorno digital deverá facilitar a solicitar com clareza, e a obter ajuda de um técnico de informática ou de pessoa com esta competência - uma "pessoa de referência em tecnologia", conforme expressão citada por Borruat (2012) em trabalho que trata dos dispositivos híbridos.
} 
assim chamados MOOC (Massive Online Open Courses), ${ }^{5}$ que são plataformas utilizadas por dezenas de milhares de pessoas espalhadas pelo mundo. Apesar da popularidade dos MOOCs, existem críticas no que se refere à falta de interações em tempo real e aos modos de avaliação (McAuley et al., 2010).

\section{Os aplicativos no contexto geral dos softwares}

Um breve panorama dos tipos de softwares disponiveis para a educação musical mostra a possibilidade de categorizá-los da seguinte forma: suporte didático, ferramenta (ou caixa de ferramentas) e produção de material musical.

Suporte didático - Jogos, atividades ou exercícios de pergunta e resposta destinados a trabalhar um conteúdo específico: leitura de notas, harmonia, percepção musical. O seu uso nos processos de ensinoaprendizagem estaria vinculado às estratégias próprias de cada professor.

Ferramenta ou Caixa de ferramentas - Aplicações destinadas a dar suporte à atividade musical. Artefatos como metrônomo, afinador de instrumentos, equalizadores, gravadores ou instrumentos virtuais são alguns exemplos destas ferramentas. Alguns softwares reúnem várias destas ferramentas, como é o caso do MusicMaster Pro. 6

Produção de material musical - Programas destinados à edição de partituras, os sequenciadores do tipo GarageBand ou CakeWalk, e os de produção de registros musicais (gravação e edição de áudio), como o Logic (antigo Pro-Tools), ou o gratuito Audacity. Alguns destes programas vêm sendo utilizados pelos professores de música adeptos das tecnologias digitais.

Note-se que os aplicativos constituem um caso particular de software. Eles são destinados principalmente aos dispositivos móveis, como smartphones ou tablets, e, ao contrário dos softwares de computadores, que são multifuncionais, possuem funções específicas. Por exemplo, o Tuner Lite se limita a fornecer uma função de afinador e outra de metrônomo.

Em busca por aplicativos referenciados por educadores em música, seja em artigos científicos ou em artigos de divulgação, obtivemos bem poucos resultados. Foram encontradas apenas experiências singulares, como aquelas repertoriadas pelo professor Wise e colaboradores da University of Canterbury, ou ainda a do professor Xydas sobre um grupo de música formado por pessoas distantes que se comunicavam por meio de seus tablets (Xydas apud Duarte; Marins, 2015, p. 13). Entre educadores musicais, é possivel encontrar portais na internet nos quais professores interessados na utilização de aplicativos em suas aulas compartilham suas experiências. São

\footnotetext{
${ }^{5}$ Alguns exemplos de curso podem ser encontrados em < https://www.mooc-list.com/tags/music $>$ ou $<$ https://www.class-central.com/subject/music>.

${ }^{6}$ Disponível em: <https://itunes.apple.com/us/app/a.p.s.-musicmaster-pro/id441595661?mt=8>.
} 
atividades estruturadas em torno de aplicativos de música. O portal de educação musical do Colégio Pedro II 7 fornece um exemplo muito interessante de compartilhamento de experiências.

Em pesquisa na webs com as palavras-chave music - education technologies, obtivemos como resultado o dado de que nos países de cultura anglo-saxônica - Estados Unidos, Inglaterra e Canadá (anglófono) - a utilização de recursos digitais é bastante difundida. Observou-se uma dezena de sites, cada um contando dezenas de aplicativos destinados à educação musical, ${ }^{9}$ número visivelmente superior ao dos países de cultura francesa.

\section{Adoção e apropriação de dispositivos digitais}

O problema da adoção e da apropriação das ferramentas digitais (aparelhos e/ou programas) se coloca no Brasil, para os educadores de música, da mesma forma que para educadores de outros países do Ocidente, incluindo aqueles nos quais a tecnologia é onipresente no cotidiano das pessoas. Os professores Zao e Frank, da Michigan State University, se interessaram pelo uso de tecnologias digitais pelos educadores, e, embora o trabalho seja de 2003 nos Estados Unidos, consideramos, com base em nossas experiências profissionais, que uma das suas constatações permanece atual:

Como a tecnologia é intrinsecamente incerta e suscetivel a falhas, os professores podem optar por não usá-la em seus cursos, a menos que haja uma forte necessidade e um apoio confiável10 (Zao; Frank, 2003, p. 809).

Esta observação é particularmente justa no uso das tecnologias digitais em música. Frequentemente nos deparamos com pequenos ou grandes percalços de natureza técnica, como erros involuntários de configuração de áudio, de midi, um cabo desconectado etc. Para evitar descontinuidade na dinâmica da aula, resultando em dispersão e/ou desinteresse dos estudantes, tais problemas necessitam de soluções rápidas.

Frisamos que a abundância de ofertas de recursos digitais/aplicativos destinados à educação musical não produz necessariamente qualidade pedagógica, pois, mesmo sendo visualmente atraentes ou apresentando recursos técnicos sofisticados, estes produtos não se propõem a responder às demandas de uma situação didática específica ou de uma dinâmica da aula. A introdução de tecnologias não representa, a priori, melhora quantitativa ou qualitativa no processo. O uso de tecnologias nos parece questionável quando

\footnotetext{
${ }^{7}$ Disponível em: <http://www.educamusicacp2.com.br/>.

${ }^{8}$ Busca exaustiva, porém, informal, realizada em jan/2017 pelos autores para este artigo.

${ }^{9}$ Exemplo de inúmeros resultados: <http://www.educatorstechnology.com/2014/02/30-ipad-apps-for-music-teachers.html>.

10 "Because technology is inherently unreliable and can break down at any time, teachers may choose not to use it in their teaching unless there is a strong need for it and reliable support."
} 
a atividade de ensino-aprendizagem já alcança os objetivos sem mediação tecnológica. Ou seja, onde não se detecta demanda explícita ou implícita de mediação tecnológica, não há por que usar tecnologia.

\section{CONCEITOS DIDÁTICOS COMO BASE PARA A VALIDAÇÃO DE}

\section{FERRAMENTAS DIGITAIS DESTINADAS AO ENSINO-}

\section{APRENDIZAGEM DA MÚSICA}

O uso das ferramentas digitais está presente em diferentes instâncias de ensino-aprendizagem da música. Plataformas de educação a distância, testes de avaliação, ferramentas de edição de textos e de música, entre outros, vão se incorporando no cotidiano dos docentes (Gohn, 2009). No entanto, a adoção efetiva pelos professores de softwares com finalidade exclusivamente didática ainda gera impasse. Com o intuito de contribuir para sanar este bloqueio, propomos que sigamos no sentido de elaborar critérios para a introdução de ferramentas digitais no processo de ensino-aprendizagem de música. Para tanto, partimos do princípio de que a validação de uma ferramenta didática, mesmo as não digitais, precisa ser estabelecida por critérios didáticos, baseando-se nos conceitos de transposição didática (Chevallard, 1991) e de situação didática (Brousseau, 2011; Terrien, 2010, 2014). Terrien tem realizado estudos considerando o ensino-aprendizado da música sob a luz desses conceitos desenvolvidos a partir de Brousseau e Chevallard e que constituem o atual campo da didática. Inspiramo-nos então nas suas abordagens para propor que a articulação da educação musical com as tecnologias digitais seja feita através de um conjunto de ações e interações que emerjam das situações de ensino-aprendizado, seja por iniciativa do aluno, seja por iniciativa do professor, ou, ainda, pelas condições sociais e materiais do meio.

\section{A situação didática}

O conceito de situação didática é elaborado a partir do ato ensinoaprendizagem propriamente dito. Para Brousseau, a situação didática consiste em

[...] um conjunto de relações explícitas ou implícitas que estabelecem entre si um aluno ou grupo de alunos, um meioambiente (incluindo eventualmente instrumentos ou objetos) e um sistema educativo (representado pelo professor) que visa fazer com que estes alunos se apropriem de um saber já constituído ou em vias de se constituir (Brousseau, 1983, p. 39). 


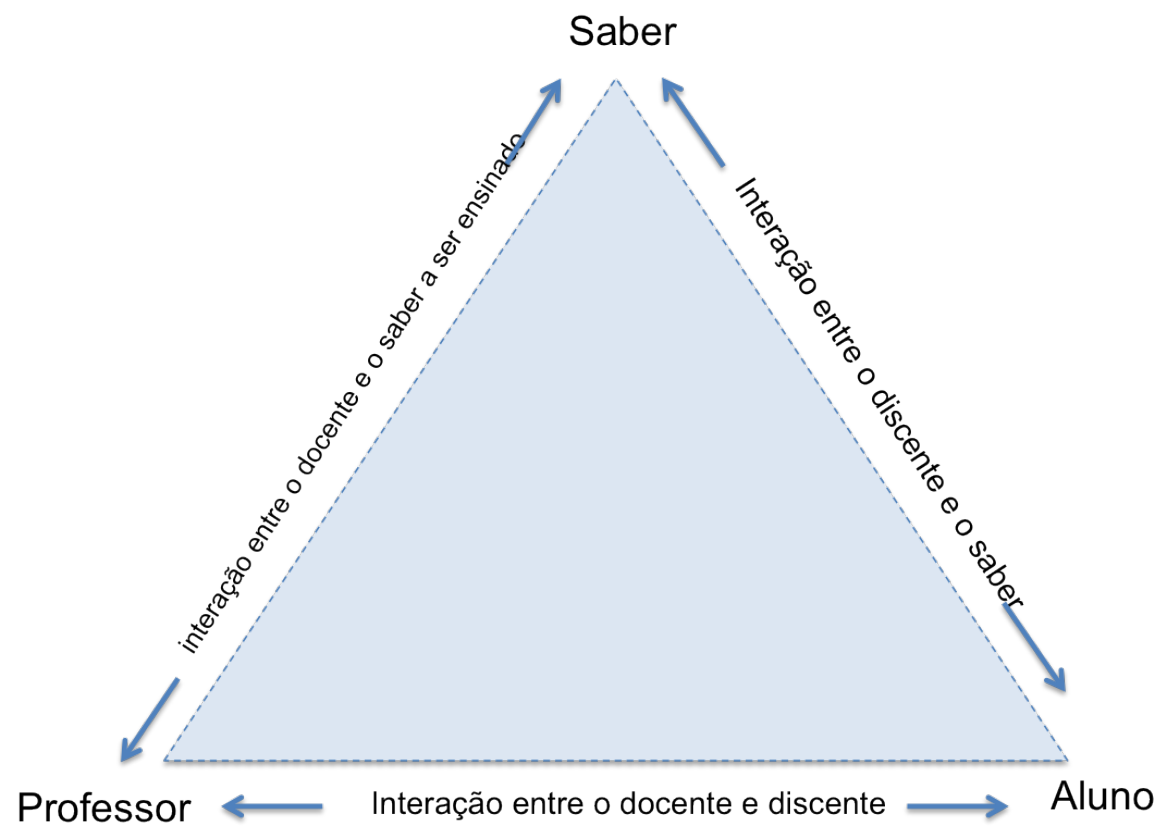

Figura 1: Triângulo pedagógico (Houssaye, 1992).

O modelo acima, na forma de um "triângulo pedagógico" (Houssaye, 1992, p. 41), ilustra o sistema de interações entre: professor/saber; aprendiz/saber; e professor/aprendiz, atores da situação pedagógica. Ao refletir sobre este modelo, Brousseau (2011) admite a existência do sistema de interações, porém, identifica outros fatores interagindo no sistema: o meio ambiente material e escolar e o sistema educativo, como fatores fortes. Ele indica, além disso, dois fatores mais discretos: a interação entre o sistema e a pessoa aluno/aprendiz. A pessoa aluno, em interação com as regras do sistema educativo; e a pessoa (a mesma) do aprendiz, como sujeito que interage com o professor e com o conhecimento:

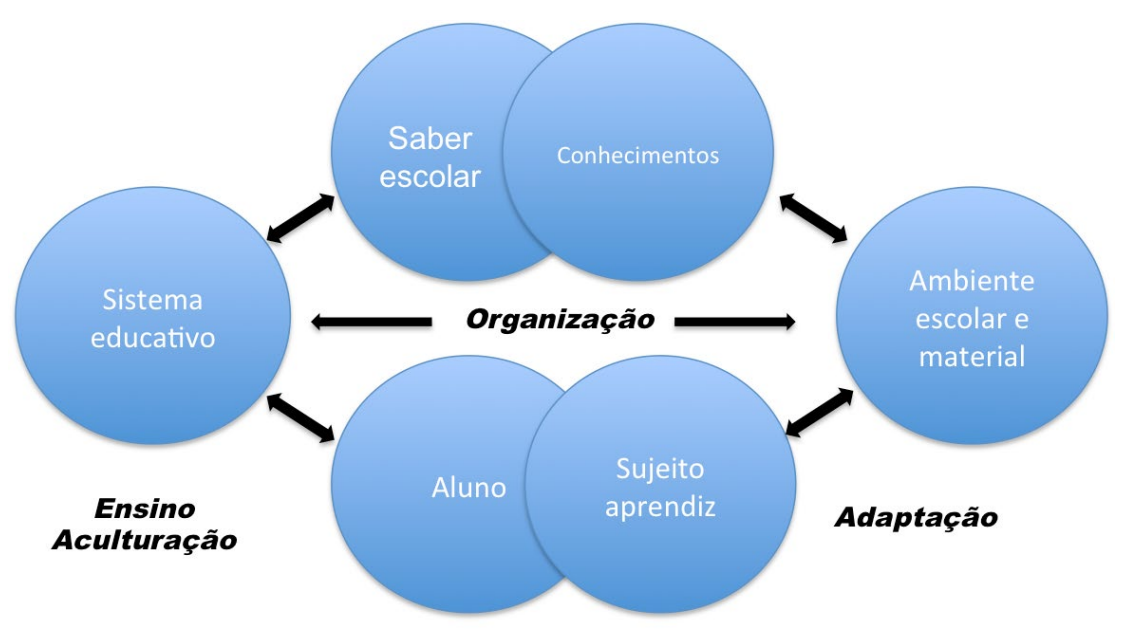

Hexágono didático

Figura 2: Hexágono didático/pedagógico (Brousseau, 2011). 
Com a expressão "interação da pessoa aluno e pessoa aprendiz", Brousseau se reporta ao duplo movimento daquele que se sujeita ao processo de ensino com as regras de um sistema educativo e que usa de procedimentos e mecanismos próprios de aprendizagem na interação com o conhecimento e com o professor. Ao atribuir um duplo estatuto ao mesmo ator, aluno/aprendiz, Brousseau (2011) identifica o indivíduo como parte do sistema escolar, com suas condições e regras, enquanto o termo aprendiz indica este mesmo indivíduo como sujeito de sua aprendizagem, mobilizando, em meio às regras de um sistema educativo, seus próprios mecanismos de aprendizagem. O mesmo acontece com o duplo status do conhecimento.

Considerando as situações didáticas como um conjunto de interações entre atores, e entre estes e o saber, o que acontece se um dispositivo digital e interativo for inserido neste sistema?

Nossa hipótese (Figura 3) é de que o dispositivo deveria se tornar o que Brousseau chama de "meio didático" (Brousseau, 1988, p. 311), ou seja, o palco da situação didática. Um palco cujos elementos da cena estão representados pelas funcionalidades que possibilitam as interações dos atores com o dispositivo. Para ilustrar nosso propósito, propomos o esquema abaixo:

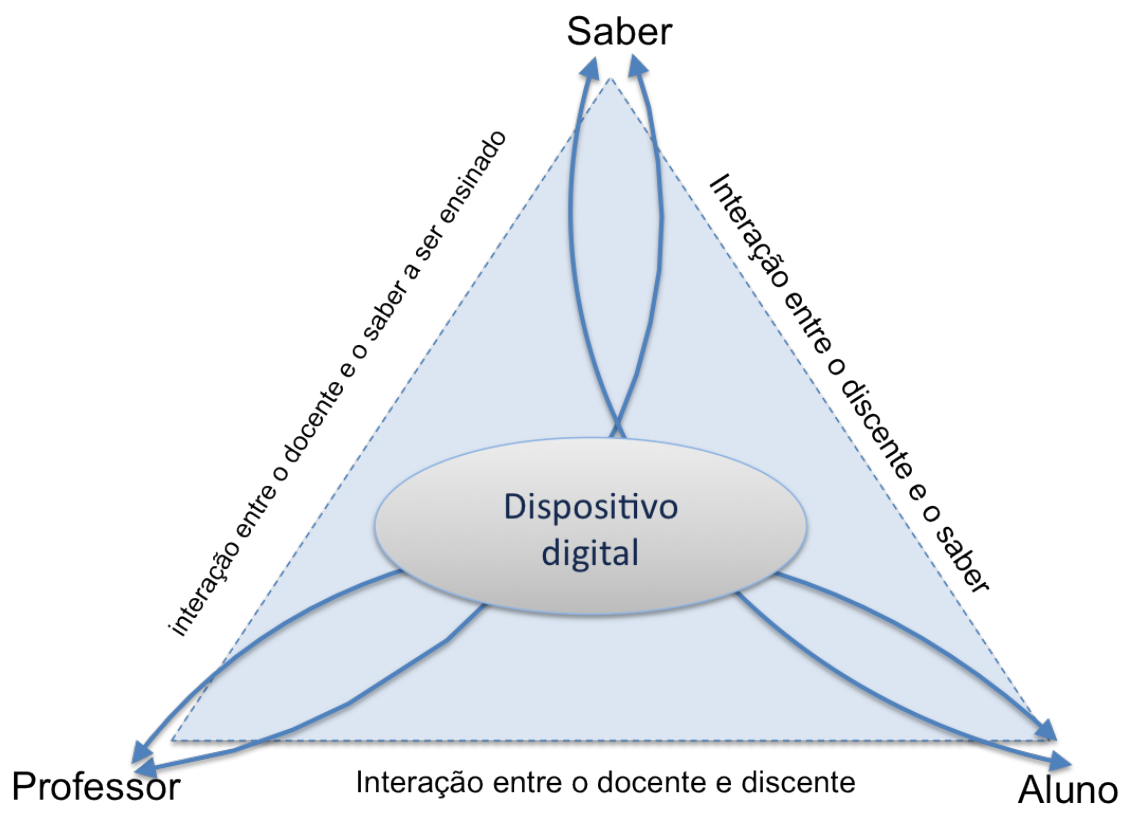

Figura 3: Modelo de interações didáticas com dispositivo digital.

$\mathrm{Na}$ perspectiva deste trabalho, o dispositivo digital intervém como um dos elementos da situação didática e, portanto, não determina o processo. Ou seja, mesmo em presença de um dispositivo tecnológico, a situação didática será conduzida pelo professor no sentido dos objetivos visados, num processo de alisamento ou estriamento, em função das demandas de um trabalho participativo/colaborativo, de um percurso exploratório, de agenciamentos e conexões não necessariamente previstos. 


\section{A transposição didática}

O conceito de transposição didática é muito caro e conhecido, desde sua criação pelo sociólogo Verret (1975), para definir o processo através do qual um saber produzido em contexto científico ou erudito ${ }^{11}$ se transforma em saber escolar (saber a ser ensinado/saber a ser aprendido). ${ }^{12}$ No entanto, Chevallard se distancia de Verret ao recusar o termo "transmissão" de saberes, usado por este último, assim como as consequentes noções de invisibilidade do saber e de centralidade da figura do professor. Ressaltando que "carecemos cruelmente de conhecimento sobre a vida 'intima' dos saberes nas salas de aula" (Chevallard apud Leite; Candau, 2004, p. 49), ele prefere falar da "transformação adaptativa" dos saberes a esse novo contexto (p. 50). Por outro lado, Leite e Candau colocam em discussão o trabalho de Chevallard (Leite; Candau, 2004) sob a luz dos textos de Perrenoud (1993, 1998), que propõe o termo "transposição pragmática" (1993, p. 26), considerando a forte ligação entre transposição e situação didática que o docente experimenta ao "gerir situações didáticas" (Perrenoud, 1993, p. 26). O autor reforça sua proposta ao afirmar que a transposição didática é também uma "tradução pragmática dos saberes para atividades, para situações didáticas", o que envolve "planificar, introduzir, animar, coordenar, levar a uma conclusão" (Perrenoud, 1993, p. 26). No Brasil, Lopes (1999, p. 208) propõe o conceito de mediação didática como um convite à reflexão sobre os processos de transformação do conhecimento em saberes ensináveis. O saber escolar está, portanto, recolocado em cena e tomado como eixo de discussão.

Segundo Lopes (1999, p. 20), a transposição didática torna "conhecimentos científicos e/ou eruditos em 'saberes escolares". Ou seja, é a "(re)construção de saberes na instituição escolar" (Lopes, 1999, p. 20). Uma "epistemologia escolar" que tem como ponto focal "a forma de apropriação do conhecimento pela escola, o processo de transposição didática que retira do conceito sua historicidade e sua problemática, constituindo novas configurações cognitivas" (Lopes, 1999, p. 20). Portanto, no ato de transposição/reconstrução de saberes, um conhecimento apropriado pela escola e não esvaziado de sua historicidade e concretude ganha valor e sentido e torna-se constitutivo dos sujeitos, sendo recortado sucessivamente e redimensionado a partir da mediação desses protagonistas. É neste sentido que a transposição está estreitamente ligada à noção de mediação didática. Uma roda de choro na prática social de referência não é o mesmo que uma roda de choro na situação didática, onde fica subjacente um processo de mediação didática que contempla os aspectos a serem ensinados. Chevallard considera o caminho que vai do saber ensinar à produção dos objetos de ensino, uma invenção que concerne ao ensino (Leite; Candau, 2004, p. 4573).

\footnotetext{
11 Tradução livre da fórmula em francês: savoir savant.

12 Tradução livre da fórmula em francês: savoir à enseigner/savoir à apprendre.
} 
Chevallard observa que o campo de ação da transposição didática extrapola as fronteiras da sala de aula. Para expressar sua observação, ele propõe a distinção entre a transposição stricto sensu (transposição didática interna) e a transposição lato sensu (transposição didática externa). No sentido stricto, o que ocorre é a passagem do saber sábio (savoir savant) para uma versão didática do saber; os elementos que fazem parte desse sistema são os professores, alunos e o saber a ser ensinado. Já no sentido lato, envolve transformações sofridas pelo saber, desde a concepção até o saber ensinado (savoir enseigné), de tal maneira que se inicia com a definição dos saberes a ensinar com base no saber ensinado (Chevallard, 1991). Porém, a gênese do sistema didático se desenvolve também no exterior da escola, em um amplo contexto social em que estariam incluidos os especialistas/cientistas, as famílias dos estudantes, as instâncias políticas de decisão, enfim, "todos os que pensam os conteúdos de ensino" (Lopes, 1999, p. 208). A este entorno social da didática, Chevallard dá o nome de noosfera (Chevallard, 1991, p. 34). A noosfera ${ }^{13}$ seria encarregada de realizar a interface entre a sociedade e as esferas de produção dos saberes, dela participando, em posições diferenciadas, contando com agentes e agências especializados no trabalho mais direto de transposição didática. Diz Chevallard:

[...] os representantes do sistema de ensino, com ou sem mandato (do presidente de uma associação de professores ao simples professor militante), encontram, de forma direta ou indireta (através do libelo da denúncia, da pressão da reivindicação, do projeto transacional, ou dos debates surdos de uma comissão ministerial), os representantes da sociedade (os pais de alunos, os especialistas da disciplina que militam pelo seu ensino, os representantes dos órgãos politicos) (Chevallard, 1991, p. 25 apud Leite; Candau, 2004, p. 60).

A discussão prossegue em torno da transposição didática, tal como foi proposta por Chevallard, quando Martinand introduz o fato de que nem todo conhecimento ensinado na escola é conhecimento acadêmico (Martinand, 2003), sendo possivel dizer que a transposição didática trata das transformações de "práticas de referência" (p. 128) - sejam elas do comércio, das atividades técnicas e artísticas - em saberes a serem ensinados.

\section{A transposição didática em música}

Como a transposição didática intervém na educação musical? A transposição (ou mediação) didática é um conceito relevante à temática "ensinar e aprender música", na investigação sobre gestão do conhecimento e gestão da sala de aula, considerando ferramentas digitais, jogos e cartografias. A música tem características que permitem situá-la como prática

\footnotetext{
${ }^{13}$ Segundo Chevallard (1991, p. 34) a noosfera media as "transações" entre o passado (conhecimentos construídos) e o porvir (conhecimentos a serem construídos).
} 
social de referência (o fazer musical), segundo o sentido dado por Martinand (2003), ou como objeto de saber (uma peça musical é suscetivel de se tornar objeto de ensino-aprendizagem). Em ambas situações é possivel identificar o processo de transposição externa, ou seja, uma expressão da atividade humana que determinadas instâncias e pressões sociais indicam como saber a ser aprendido. Por exemplo, as "batidas", fórmulas rítmicas de acompanhamento, que caracterizam os subgêneros do choro (samba-choro, maxixe, valsa) (Fernandes; Pulici, 2016), ou ainda a maneira de realizar as sincopes quando se canta ou toca uma melodia de samba.

Nas palavras de Terrien, que discorre sobre a transposição didática em música, considera-se que

O trabalho de transposição didática é que permite ao professor organizar em fases sucessivas a superação das dificuldades. [...] O trabalho de transposição didática é revelar as microdificuldades, permitindo prepará-las para [que o aluno possa] superá-las mais facilmente ${ }^{14}$ (Terrien, 2012, p. 9).

Para Terrien, o papel da transposição didática seria o de analisar um saber musical em todas as suas dimensões e seus aspectos: a música e suas relações com a musicologia, técnicas etc. e com o mundo acadêmico e científico. Só deste modo o professor estaria apto a organizar o processo de ensino-aprendizagem na perspectiva de um projeto pedagógico globalizante.

Como forma de aplicar ao ensino de música os conceitos vistos até aqui, propomos uma mediação didática (e a invenção de objetos de ensino, ferramentas digitais etc.) que leve o aluno "a dúvidas, suposições e hipóteses, ao conhecimento especulativo, à pesquisa e à investigação" (Koellreutter, 1994, p. 13). A mediação didática, a construção de objetos de ensino e a produção de saberes implicam mais do que a preparação da "superação de dificuldades" (ênfase de Terrien), pois lidam com (respondem a e/ou concorrem para) a proliferação de possibilidades de aproximação de um sujeito que é afetado pelas qualidades de um material-força e que afeta esses materiais com seus recortes e conexões, produzindo agenciamentos diversos.

\section{SITUAÇÃO E TRANSPOSIÇÃO DIDÁTICAS EM DOIS CASOS DE PESQUISA EM EDUCAÇÃO MUSICAL}

Para fornecer exemplos de operacionalização destes conceitos, apresentamos aqui duas experiências: (1) um dispositivo de apoio ao ensino e aprendizado do solfejo, especificado e desenvolvido por um dos autores deste ensaio na sua tese de doutorado (Aristides, 2015); e (2) a do grupo de pesquisa "Música e Educação Brasileira", na linha "ensinar e aprender música”. Estes

\footnotetext{
14 “Le travail de transposition didactique permet à l'enseignant d'organiser l'appropriation des difficultés par phases successives. [...] Le travail de transposition didactique révèle ces micros difficultés et permet de les préparer pour mieux les surmonter."
} 
dois casos de pesquisa ilustram o tríplice sistema de interações didáticopedagógicas apresentado no triângulo de Houssaie (1992): professor < > saber, aprendiz $<>$ saber e professor $<>$ aprendiz.

O dispositivo LOCREAM: especificação e desenvolvimento de um suporte ao ensino-aprendizagem do solfejo

Em sua tese de doutorado (Aristides, 2015), o coautor deste ensaio investiga a influência de uma atividade de criação de melodias para o aprendizado do solfejo. Para testar as hipóteses de trabalho, notadamente o ganho em termos de aprendizagem da leitura de partituras tonais, foi desenvolvido um protótipo de dispositivo digital para a construção de melodias, chamado LOCREAM. Este desenvolvimento constituiu para o coautor, professor de música, uma ocasião de colocar em prática a questão do docente produtor de ferramenta digital.

\section{Premissas para o desenvolvimento do dispositivo LOCREAM}

A leitura de partitura foi tomada como a prática de referência (Martinand, 2003) para a transposição didática. A premissa foi a de que os bons leitores leem grupos de notas, ou grupos de significantes musicais (Nattiez, 2004; Lerdahl; Jackendoff, 1977). Assim, decidiu-se por um desenho de ambiente virtual em que o usuário manipule grupo de notas, considerando que estes grupos estão carregados de significação tonal (Nattiez, 2004). A partir desta articulação de conceitos é que foi desenvolvido o ambiente virtual LOCREAM, no qual o usuário, estudante de solfejo, tem à disposição um conjunto de grafismos a serem combinados para construir uma melodia.

\section{Obtenção dos fragmentos do dispositivo LOCREAM}

Os fragmentos são obtidos através da segmentação em pequenas sequências melódicas de 3 a 8 notas. O ponto de corte é determinado pela intuição de quem segmenta, tomando como critérios a carga significante e o desenho formado pelas inflexões do trecho. Obtivemos assim segmentos que podem ser classificados segundo a seguinte tipologia: (A) para segmento com ponto de inflexão superior, (V) para segmento com um ponto de inflexão inferior, (N) para um segmento com uma inflexão superior seguida de uma inferior. Os tipos $(Z, W, M)$ seguem a mesma lógica. A tipologia está representada pelos desenhos mostrados na figura a seguir. A coluna 1 mostra o tipo, a segunda coluna mostra o desenho simbólico e a terceira, um exemplo em notação musical correspondendo ao tipo de segmento: 


\begin{tabular}{|c|c|c|}
\hline Tipo & Simbolo & Notação \\
\hline A & & \\
\hline V & & \\
\hline $\mathrm{N}$ & & \\
\hline Z & & \\
\hline W & & 92 \\
\hline$M$ & & \\
\hline
\end{tabular}

Figura 4: Tipologia de segmentos melódicos (Aristides, 2015).

A Figura 4 mostra o tipo de segmento, a figura que o representa e a melodia que está sendo representada. Cada figura representa um fragmento melódico, e o usuário clica em cada uma para ouvi-la e realizar uma combinação. O usuário ouve a combinação e salva o resultado se este lhe convém, atrelando o fragmento seguinte, até completar uma frase musical composta de 8 (oito) fragmentos.

Este caso ilustra a observação expressa anteriormente sobre o duplo status da melodia, ao mesmo tempo saber de referência (Martinand, 2003) e objeto de saber sábio, na medida em que a melodia tonal é objeto de diversos tipos de análises. Do corpus tonal, extraiu-se uma série de objetos (fragmentos de melodias tonais), de maneira a ser possível, a partir destes fragmentos, reconstruir um novo objeto sábio.

O ambiente LOCREAM permite ao professor propor situações didáticas em torno da atividade de construção de melodias, podendo ser, por exemplo, uma situação que auxilie na (re)construção de conhecimentos sobre estruturas melódicas.

\section{O grupo de pesquisa "Música e Educação Brasileira"}

Na linha de pesquisa "Ensinar e Aprender Música”, 15 o grupo citado vem trabalhando com o repertório vocal brasileiro, tomando músicas da prática social de referência e mapeando possibilidades de sua transposição didática.

\footnotetext{
${ }^{15}$ Integra o grupo de pesquisa "Música e educação brasileira", cadastrado no CNPq: <http://dgp.cnpq.br/dgp/espelhogrupo/0795713097970538>.
} 
Parte-se assim para uma primeira transposição didática, analisando as potencialidades de músicas da prática social de referência para o contexto pedagógico, antes mesmo de se iniciar o trabalho numa situação didática concreta, com sujeitos que reconfigurarão o conhecimento. Esse mapeamento prévio é condição para se desenhar a segunda transposição didática, a saber, a construção de objetos de ensino e dispositivos digitais potenciais aliados nas atividades didático-pedagógicas.

Ao se preparar para a aula, nessa pedagogia aberta que conecta elementos que forçam a pensar (Santos, 2011, 2012, 2015a, 2015b), o professor-gestor faz a imersão num objeto-música, prática de referência social - no caso, o Hino Nacional Brasileiro (HNB), que aqui elegemos para ilustrar este artigo.

Sempre está em mente a questão: em que medida a introdução de um dispositivo digital pode representar ganho em termos de ensino-aprendizado e como dinamizador das interações entre os diversos atores da situação didática? Os elementos de resposta desse projeto de introdução do dispositivo devem emergir da análise do sistema tríplice de interações (Figura 3), indicando a operacionalização da relação aprendiz $<>$ saber e professor $<>$ aprendiz.

\section{Prolegômenos para uma abordagem do HNB na sala de aula}

O HNB será considerado como um território com múltiplas direções, recortes e agenciamentos. Portanto, no processo de transposição didática, há uma primeira transformação do objeto artístico (o hino) em "saber ensinável", considerando múltiplas dimensões, aspectos sociomusicológicos, técnicos etc., e envolvendo processos cognitivos de escuta/recepção, emissão, execução, análise, invenção. O hino é produto cultural e histórico, manifestação da arte musical, prática de sujeitos concretos. Envolve situações de escuta/recepção, de execução e performance, diversas contextualizações e formas de enunciação musical. Aspectos musicológicos, saberes técnicos e notacionais, "prováveis dificuldades" rítmicas e melódicas são pontos de interesse nesse mapa exploratório. O HNB pode ainda ser lugar de exercícios de experimentação e invenção.

\section{A produção de objetos de ensino para o HNB}

Dentre alguns objetos de ensino produzidos, Regina M. Santos, participante do grupo de pesquisa e coautora do presente artigo, sugeriu uma série de cartões-fichas, cada um representando as alturas relativas de uma semifrase do hino nacional, um gesto ou conjunto de gestos musicais. Cada cartão-ficha tem alguns propósitos, no processo de tornar "ensinável" um saber de referência tomado da prática social. Vejamos esses cartões-fichas e suas possibilidades de servirem como dispositivos/artefatos nesse imbricado processo de aprendizagem-ensino. 


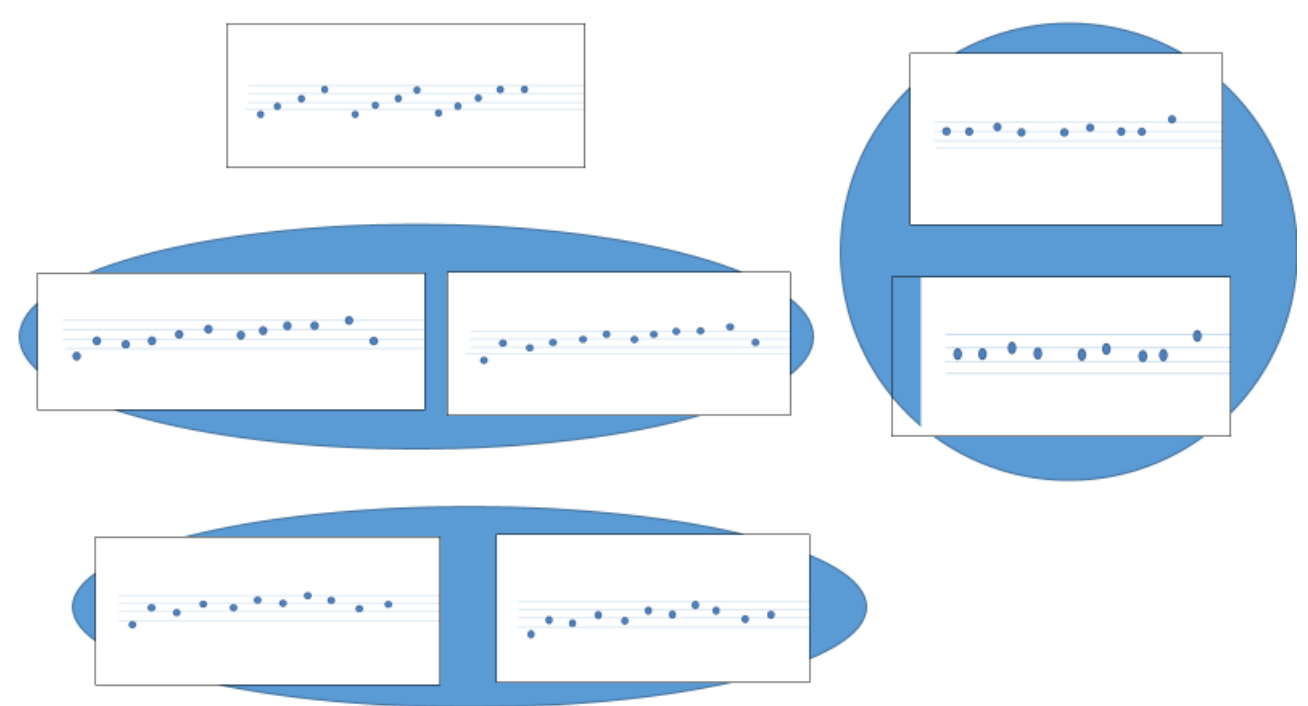

Figura 5: Hino Nacional Brasileiro: alguns gestos musicais partituras de alturas (SANTOS, 2017-18) ${ }^{16}$.

Podemos qualificar a representação trazida nestes cartões-fichas como uma partitura de alturas ${ }^{17}$. Em seguida, apresentamos o mapeamento de algumas das possibilidades de mediação/transposição usando as cartõesfichas:

- relacionar os cartões entre si, identificando semelhanças e diferenças nas imagens;

- identificar e ordenar os cartões, relacionando-os às imagens sonoras que representam (sejam elas tomadas da memória, de uma execução ao vivo ou de uma gravação);

- seriar e entoar os cartões-fichas, seguindo um "regente";

- descobrir cartões-fichas que faltam, gestos musicais que não estão grafados, criando seus registros;

- expressar o gráfico com movimento corporal, usando uma fonomímica correspondente;

- fazer a leitura do registro melódico, considerando variações de altura grafadas na mesma linha ou espaço, exigindo um acordo dos sujeitos sobre como sinalizar tal variação;

- usar um instrumento de teclas como recurso visual, atestando a diferença na entonação e justificando o emprego de sinais (de

\footnotetext{
${ }^{16}$ As ilustrações datam de 2017/2018 e estão em fase de elaboração pela coautora deste artigo. Esta nota vale para todas as figuras desta seção, acompanhadas da referência de Santos.

17 Usamos notação em pauta muda e gradativa, evitando linhas suplementares, que seriam pura abstração. Por que linhas suplementares "inferiores", quando há linhas sobrando acima? De igual forma, as 5 linhas do pentagrama não se justificam, não são requeridas para o registro do movimento melódico. Quando necessário, podem vir a ser agregadas pelos estudantes, que terão compreendido a lógica das linhas e espaços.
} 
alteração, já codificados ou não) necessários na grafia, considerando diferenças qualitativas dos intervalos.

Destacamos um destes cartões-fichas (Figura 6) que representaria o gesto musical da primeira semifrase do HNB:

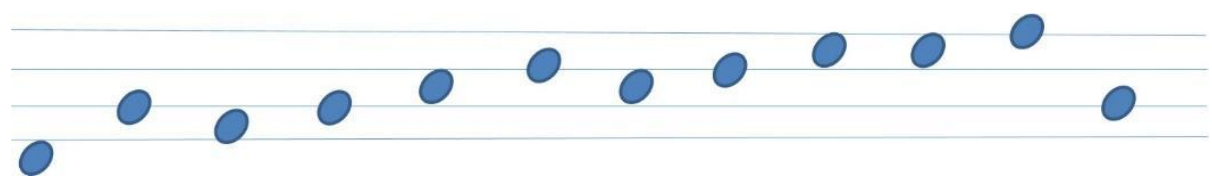

Figura 6: Gesto musical da primeira semifrase do Hino Nacional Brasileiro (Santos, 2017-18).

No cartões-fichas trazido na Figura 7, por exemplo, identificado o trecho, deve-se completar o segmento que falta, localizando as notas nos respectivos espaços e linhas da pauta, arrastando-as enquanto ouvem, cantam ou conferem sua execução no teclado.

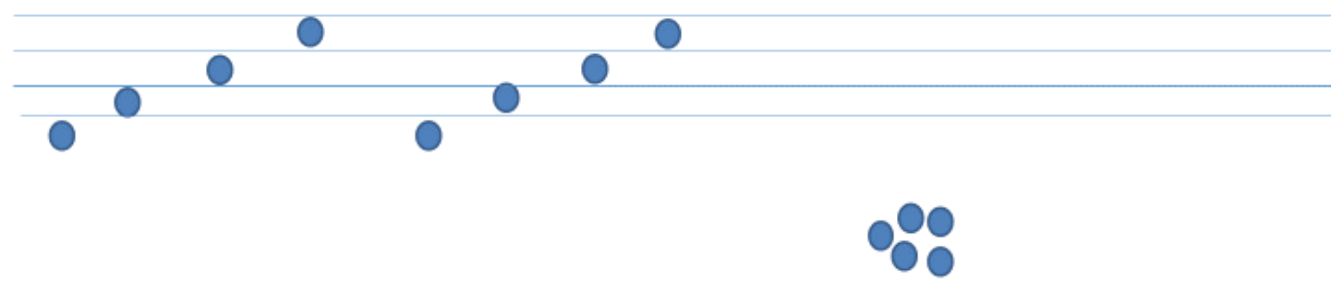

Figura 7: Identificar este segmento melódico do HNB, colocando as notas do trecho final nas posições correspondentes no registro gráfico (Santos, 2017-18).

O mesmo ocorre com este outro cartões-ficha (Figura 8):
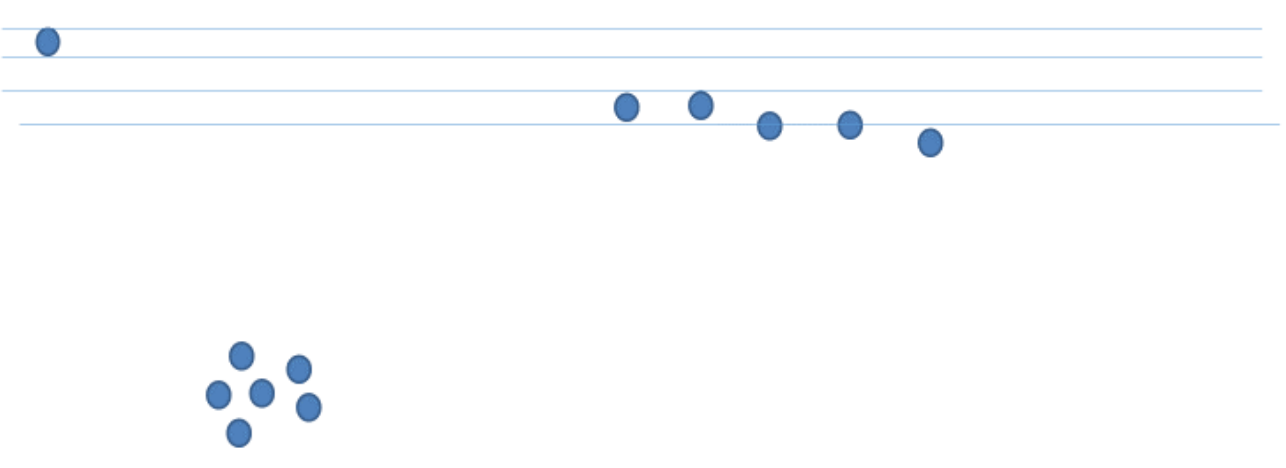

Figura 8: Identificar este segmento melódico do HNB, colocando as notas nas alturas correspondentes neste registro gráfico (Santos, 2017-18). 
O gráfico trazido no cartão-ficha a seguir (Figura 9) desafia o usuário/aprendiz a relacionar os gráficos-roteiros às semifrases apresentadas no conjunto de cartões (Figura 5). Há o retorno de uma ideia musical em movimento quebrado, ganhando abertura do plano a partir de um salto inicial. O desafio seguinte é recompor essas microestruturas e reagrupar incisos, das menores às maiores unidades recortadas.
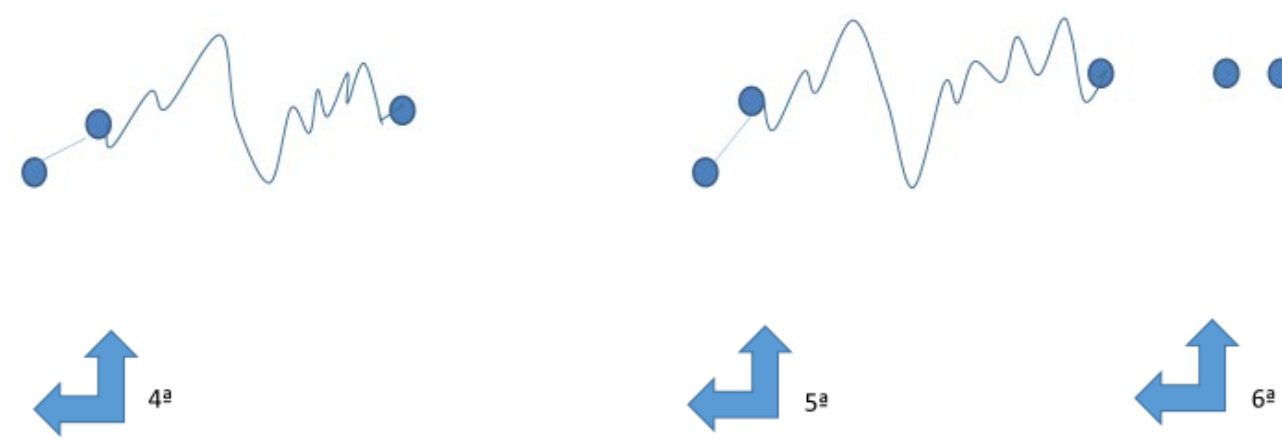

Figura 9: Grafia analógica de segmentos do HNB (Santos, 2017-18).

Os cartões-fichas e a proposta de decomposição do hino em segmentos de frases ou gestos musicais estão sendo objeto de consideração no grupo de pesquisa, do qual faz parte o coautor do presente artigo, que sugeriu aproximá-las do procedimento previsto para o dispositivo LOCREAM, constituindo mais um passo no processo de transposição didática.

\section{COMPETENCIAS PARA CONCEBER, ESPECIFICAR, PRODUZIR E} AVALIAR SOFTWARES

O processo de transposição didática, visando a construção de um dispositivo digital, deve se dar a partir das competências atuais em tecnologias apresentadas pelos potenciais utilizadores ${ }^{18}$ (Silvino; Abrahão, 2002). Ao tomar este cuidado, a introdução de um dispositivo digital tem mais chances de engendrar um ganho em termos de ensino-aprendizagem e de cumprir o papel de dinamizador das interações entre os diversos atores. Porém, para justificar de maneira fundamentada o uso de um aplicativo ou outro software, torna-se necessário realizar experiências controladas, seja por parâmetros quantitativos, seja por parâmetros qualitativos com elementos quantitativos. Sugerimos aqui dois procedimentos que poderão ser úteis para o educador que pretende adotar um software: (1) o educador se apropria da ferramenta e, utilizando sua vivência, faz uma projeção sobre a efetividade da introdução da ferramenta em sala de aula; e (2) o educador se apropria da

\footnotetext{
18 Por exemplo, quase todos os editores de partituras permitem a inserção de uma nota na pauta através de um simples clique de mouse em um dos espaços ou linhas. Isto é assim porque clicar é um gesto básico no uso corrente da informática, da mesma forma que escrever uma nota na pauta o é para quem trata com a escritura musical.
} 
ferramenta e reúne um número reduzido de alunos para testar a efetividade da ferramenta antes de propô-la ao grupo inteiro.

Após tratar da capacidade para avaliar, validar e lidar com aplicativos, propomos discutir o papel do educador musical como produtor de conteúdo, incluindo o de produtor de conteúdo digital. $O$ foco recai, portanto, no desenvolvimento de competências básicas para a concepção de softwares e na apropriação de ferramentas computacionais para a produção de aplicativos.

O que nos parece interessante é que, ao se tornar produtor de meios digitais de ensino-aprendizado, o(a) docente deverá mobilizar suas experiências na concepção de situações didáticas, aprendendo a expressá-las em termos de especificação de softwares. A competência almejada é a de, uma vez definido o objetivo, saber decompor a atividade em objetivos intermediários, ou seja, em ações que os estudantes devem realizar na interface do software de aprendizagem para alcançar o objetivo proposto.

\section{CONSIDERAÇÕES FINAIS}

Neste artigo consideramos que ferramentas digitais são aliadas nas atividades didático-pedagógicas em música, numa pedagogia aberta. Nesta perspectiva, tratamos a transposição e a situação didática como os dois conceitos centrais tanto para a realização de sequências como para a produção de objetos de aprendizagem. Consequentemente, sugerimos que tanto o desenvolvimento como a adoção e o uso das ferramentas digitais por parte dos professores de música sejam validados através destes conceitos.

Concluímos enfatizando que a introdução da ferramenta digital na situação didática esteja condicionada ao ganho efetivo no processo de ensino ou em termos do aprendizado, bem como ao seu papel como dinamizador das interações entre os diversos atores (saber/conhecimento, professor e aluno). Não existe uma prescrição genérica, ampla, de como introduzir uma ferramenta digital em situação de ensino-aprendizado. O melhor meio de conduzir a integração é a consciência de que se trata sempre de uma situação imanente, singular, processual, podendo ser estimada sua eficácia apenas em cada situação específica, considerando a complexa rede de interações, processos cognitivos e aspectos enredados na transposição didática.

\section{REFERENCIAS}

ARISTIDES, Marcos A. M. Vers un dispositif numérique pour l'enseignement apprentissage du solfège: convergence de la pédagogie et de la didactique de la musique avec la technologie numérique. 2015. Tese (Doutorado em Ciências da Educação) - Faculté de Psychologie et Sciences de l'Éducation, Université de Genève, Genève, 2015. 
BORRUAT, S. et al. Dispositifs hybrides, nouvelle perspective pour une pédagogie renouvelée de l'enseignement supérieur. In: DESCHRYVER, N. ; CHARLIER, B. HY-SUP: Programme Education et formation tout au long de la vie: rapport final. Genève: Université de Genève, 2012. p. 154-190.

BRASIL. Ministério da Educação. Base Nacional Comum Curricular. Versão final. Brasília: MEC, dez. 2017.

BROUSSEAU, G. Le rôle central du contrat didactique dans l'analyse et la construction des situations d'enseignement et d'apprentissage des mathématiques. In: COLLOQUE DE LA TROISIĖME UNIVERSITÉ D'ÉTÉ DE DIDACTIQUE DES MATHÉMATIQUES D’OLIVET, 3.,1984. 11 p.

BROUSSEAU, G. La théorie des situations didactiques en mathématiques. Education \& didactique, v. 5, n. 1, p. 101-104, 2011.

BROUSSEAU, G. Le contrat didactique: le milieu. Recherches en Didactique des Mathématiques, Rennes, v. 9, n. 3, p. 309-336, 1988.

BROUSSEAU, G. Théorie des situations didactiques. Grenoble: La pensée sauvage, 1998. Disponivel em: <http://id.erudit.org/iderudit/000137ar>. Acesso em: 30 nov. 2014.

CHEVALLARD, Y. La transposition didactique: du savoir savant au savoir enseigné. 2. édition revue et augmentée, en coll. avec Marie-Alberte Joshua, 1re édition 1985 ed. Grenoble: Ed. La Pensée Sauvage, 1991.

DELEUZE, Gilles. Diferença e Repetição. 2. ed. Rio de Janeiro: Graal, 2006.

DOLL, William E. Currículo: uma perspectiva pós-moderna. Porto Alegre: Artes Médicas, 1997.

DUARTE, Alex; MARINS, Paulo Roberto. Um estudo sobre a utilização de aplicativos para tablets e smartphones no ensino da música. In:

CONGRESSO NACIONAL DA ASSOCIAÇÃO BRASILEIRA DE EDUCAÇÃO MUSICAL, 22., 2015, Natal. Anais... Natal: Escola de Música da UFRN, 2015. p. $1-13$.

FERNANDES, D. C.; PULICI, C. M. Gosto musical e pertencimento social: O caso do samba e do choro no Rio de Janeiro e em São Paulo. Tempo Social, v. 28 , n. 2 , p. 131,6 set. 2016.

GALlO, Silvio. Deleuze \& a Educação. Belo Horizonte: Autêntica, 2003.

GOHN, Daniel. Educação musical a distância: abordagens e experiências. São Paulo: Cortez, 2011.

HOUSSAYE, Jean. Le triangle pédagogique. Berne: Peter Lang, 1992. 
KOELLREUTTER, Hans J. O Humano: objetivo de estudos musicais na escola moderna. In: SIMPÓSIO PARANAENSE DE EDUCAÇÃO MUSICAL, 3., 1994, Londrina. Anais... Londrina: SPEM, 1994. p. 10-17.

LEITE, Miriam; CANDAU, Vera. Yves Chevallard e o conceito de transposição didática. In: Contribuições de Basil Bernstein e Yves Chevallard para a discussão do conhecimento escolar. Rio de Janeiro: PUC, 2004. p. 45-73.

LERDAHL, Fred; JACKENDOFF, Ray. Toward a Formal Theory of Tonal Music. Journal of Music Theory, v. 21, n. 1, p. 111, 1977.

LOPES, Alice Ribeiro Casimiro. Conhecimento escolar. ciência e cotidiano. Rio de Janeiro: EdUERJ Rio de Janeiro, 1999.

MARTINAND, Jean-Louis. La question de la référence didactique $d u$ curriculum. Investigações em Ensino de Ciências, v. 8, n. 2, p. 125-130, 2003.

MCAULEY, A. et al. The MOOC model for digital practice. [S.1.]: Improving Canada's Digital Advantage: Strategies for Sustainable Prosperity by synthesizing, 2010. Disponivel em:

<http://www.academia.edu/download/43171388/MOOC_Final.pdf>. Acesso em: 10 set. 2016.

MORAN, José Manuel. Integrar as tecnologias de forma inovadora. In: p.36-46. Novas Tecnologias e Mediação Pedagógica. São Paulo: Papirus, 2013.

NATTIEZ, Jean-Jacques. La signification musicale. In: NATTIEZ, JeanJacques. Une encyclopédie pour le XXIe siècle. Les savoirs musicaux. Vol. 2. Paris: Actes sud/Cité de la musique, 2004. p. 256-260.

ONU - ORGANISATION DES NATIONS UNIES. Objectifs du Millénaire pour le développement. Vol. 25, 2011. Disponivel em: <http://www. un. org/fr/millenniumgoals / > .

PAIVA, V. M. de O. Ambientes virtuais de aprendizagem: implicações epistemológicas. Educação em Revista, v. 26, n. 3, p. 353-370, 2010.

PERRENOUD, P. Práticas pedagógicas, profissão docente e formação: perspectivas sociológicas. Lisboa: Dom Quixote, 1993.

PERRENOUD, P. La transposition didactique à partir de pratiques: des savoirs aux compétences. Revue des sciences de l'éducation, v. 24, n. 3, p. 487-514, 1998.

PERRENOUD, P. Construir as competências desde a escola. Trad. Bruno Magne. Porto Alegre: Artes Médicas Sul, 1999a. 
PERRENOUD, P. Avaliação: da excelência à regulação das aprendizagens entre duas lógicas. Trad. Patrícia Ramos. Porto Alegre: Artes Médicas Sul, 1999b.

RABARDEL, P.; SAMURÇAY, R. De l'apprentissage par les artefacts à l'apprentissage médiatisé par les instruments. In: BARBIER, J.-M.; DURAND, M. Sujets, activités, environnements. Paris: Presses Universitaires de France, 2006. p. 31. Disponivel em: <http://www.cairn.info/sujetsactivites-environnements--9782130543374-page-31.htm>. Acesso em: 25 ago. 2018.

SANTOS, Regina Marcia S. Já não chega do modelo da recognição? In: SEMINÁRIO NACIONAL DE PESQUISA EM MÚSICA DA UFG/I SEMINÁRIO NACIONAL DO FÓRUM LATINO-AMERICANO DE EDUCAÇÃO MUSICAL, 17., 2017, Goiânia. Anais... Goiânia: SEMPEM/FLADEM Brasil, 2017. p. 480-489.

SANTOS, Regina Marcia S. O menino do violão: a escola e a educação musical em família. Revista da ABEM, Londrina, v. 19, n. 25, p. 41-52, 2011.

SANTOS, Regina Marcia S. Um paradigma estético para o currículo. In: SANTOS, R. M. S. et al. Música, cultura e educação: os múltiplos espaços de educação musical. 2. ed. amp. e atual. Porto Alegre: Sulina, 2012. p. 251292 .

SANTOS, Regina Marcia S. O jogo-cartografia na pedagogia do afeto. In: ENCONTRO ANUAL DA ASSOCIAÇÃO BRASILEIRA DE EDUCAÇÃO MUSICAL, 22., 2015, Natal. Anais... Natal: ABEM, $2015 a$.

SANTOS, Regina Marcia S. Práticas de Ensino de Música: os fios da marionete ou os fios de Ariadne? Revista da ABEM, Londrina, v. 23, n. 34, p. 110-124, jan./jun. 2015b.

SILVINO, Alexandre; ABRAHÃO, Júlia. Navegabilidade e inclusão digital: usabilidade e competência. RAE-eletrônica, 00059, p. 2-17, 2002.

TERRIEN, Pascal. De la musique à l'enseignement: la transposition didactique. La Revue du Conservatoire, Réflexions et matériels pédagogiques. n. 4, p. 1-11, 2014.

TERRIEN, Pascal. Pour une didactique de l'enseignement musical. Les didactiques en question(s). Etat des lieux et perspectives pour la recherche et la formation. De Boeck Supérieur ed. Bruxelles: Marie-Laure Elalouf, Aline Robert, Anissa Belhadjin, Marie-France Bishop, 2012. p. 170-179.

TERRIEN, Pascal. Quelques perspectives pour une didactique de l'enseignement musical. In: ACTES DU COLLOQUE INTERNATIONAL REGARDS DES DIDACTIQUES, Octobre 2010, Toulouse. Anais... Toulouse: IUFTM, Octobre 2010. p. 1-13. 
VEIGA, Marise Schmidt. Computador e Educacão? Uma ótima combinação. In: BELLO, José Luiz de Paiva. Pedagogia em Foco. Petrópolis: [S.n.], 2001.

VERRET, M. Le Temps des études ... Lille: Atelier Reproduction des thèses, Université Lille III, 1975.

ZHAO, Y.; FRANK, K. A. Factors Affecting Technology Uses in Schools: an ecological perspective. American Educational Research Journal, 00881, v. 40, n. 4, p. 807-840, 1 jan. 2003.

Marcos André Martins Aristides é pos-doc bolsista FUNCAP/CAPES; professor convidado do PROFARTES UFC Campus Sobral. Em 2017 foi avaliador da Feira de Ciência e Engenharia, colaborador na organização da feira. Em 2016, ministrou Mini-curso de música educação e tecnologias no X encontro ABEM Sudeste. Desde 2010, colaborador externo da unidade de Tecnologias para a Formação e Aprendizagem (TECFA) da Universidade de Genebra.

Regina Márcia Simão Santos é docente da Universidade Federal do Estado do Rio de Janeiro - UNIRIO (aposentada). Doutora em Comunicação, Mestre em Educação e Bacharel em Piano pela UFRJ, Licenciada em Música pela Universidade Federal do Estado do Rio de Janeiro (UNIRIO) e com cursos de especialização em educação, em didática da música e ensino superior, realizou estudos sistemáticos sobre pedagogia, composição e estética musical com H J Koellreutter e sobre etnomusicologia com A Seeger. Desenvolve pesquisas em educação musical, sendo autora de textos acadêmicos em publicações nacionais e internacionais. 